EGU21-2075, updated on 18 May 2021

https://doi.org/10.5194/egusphere-egu21-2075

EGU General Assembly 2021

(c) Author(s) 2021. This work is distributed under

the Creative Commons Attribution 4.0 License.

\title{
DecTephra: A new database of Deception Island's tephra record (Antarctica
}

\author{
Joaquin Hopfenblatt ${ }^{1}$, Adelina Geyer ${ }^{1}$, Meritxell Aulinas ${ }^{2}$, Antonio Polo Sánchez ${ }^{1}$, and Antonio \\ Álvarez-Valero ${ }^{3}$ \\ ${ }^{1}$ Geosciences, GEO3BCN - CSIC, Lluis Sole i Sabaris s/n, 08028, Barcelona, Spain (joaquinhopfenblatt@gmail.com; \\ ageyer@geo3bcn.csic.es; polosanchezantonio@gmail.com) \\ ${ }^{2}$ Departament de Mineralogia, Petrologia i Geologia Aplicada, University of Barcelona, Marti Franques s/n, 08028, \\ Barcelona, Spain (meritxellaulinas@ub.edu) \\ ${ }^{3}$ Departamento de Geología, Universidad de Salamanca, 37008 Salamanca, Spain (aav@usal.es)
}

Deception Island is the most active volcano in the South Shetland Islands (Antarctica) with more than 20 eruptions in the in the last two centuries, including the 1967, 1969 and 1970 most recent eruptive events, and three episodes of volcanic unrest since 1990 (1992, 1999 and 2014-2015). Since the discovery of Deception island in 1820, the number of scientific bases, touristic activities, and air and vessel traffic in the region, have considerably increased. Only the Antarctic Peninsula region, together with the South Shetland Islands, hosts 25 research stations and 3 summer field camps, which are located inside or within a $150 \mathrm{~km}$ radius distance from this active volcano. Nearby, the Palmer Archipelago and the north-western coast of the Antarctic Peninsula are both important tourist destinations exceeding 30,000 visitors per year with a significant increase in vessel traffic during the tourist season. This escalation in the amount of exposed infrastructure and population to a future eruption of Deception Island clearly urges the need to advancing our knowledge of the island's volcanic and magmatic history and developing improved vulnerability analyses and long-term volcanic hazard assessments. However, past attempts to construct a volcanic hazard map of Deception have always been limited by the lack of a complete eruption record. In this sense, volcanic ash layers found in marine and lacustrine sediment cores, and glaciers outside Deception Island can provide valuable information to: (i) determine the size and explosiveness of past eruptive events; (ii) assess the extent of their related hazards (e.g. ash fall out); (iii) complete the eruption record of the island; and (iv) estimate the island's eruption recurrence over time.

In this work, we provide a detailed, and up-to-date, revision of the current knowledge on Deception Island's tephra record. For this, we have compiled the DecTephra (Deception Island Tephra Record) database, which seeks recording the most relevant information of all up today known tephra layers with Deception Island as presumed source vent. DecTephra database includes 335 tephra layers (including cryptotephras) found in marine/lacustrine sediment and ice cores. For each tephra layer, we have compiled information regarding: (i) location (e.g. latitude, longitude, region) and characteristics of the sampling site (e.g. length of the sediment or ice core); 
and (ii) tephra characteristics (e.g. age, chemistry, granulometry). The analysis of the information included in this new database shows that Deception Island's tephras can be observed at numerous proximal $(<150 \mathrm{~km})$ sampling sites distributed all along the South Shetland Islands but also as far as in the Scotia Sea $(>1,000 \mathrm{~km})$ and the South Pole $(>2,900 \mathrm{~km})$. Also, identified isochronous tephra horizons allow defining periods of higher explosive eruptive activity in the island during the Holocene.

This research is part of POLARCSIC and PTIVolcan research initiatives. This research was partially funded by the MINECO projects VOLCLIMA (CGL2015-72629-EXP) and VOLGASDEC (PGC2018-095693-B-I00)(AEI/FEDER, UE). A.P.S is grateful for his JAE_Intro scholarship (JAEINT_20_00670). 